\title{
Job Displacement Risk and the Cost of Business Cycles
}

\author{
November, 2004 \\ Tom Krebs* \\ Brown University ${ }^{\dagger}$
}

\begin{abstract}
This paper analyzes the welfare costs of business cycles when workers face uninsurable job displacement risk that has a cyclical component. Using a simple general equilibrium model with incomplete markets, this paper shows the following result: for sufficiently high degree of risk aversion (at least one), cyclical variations in the long-term earnings losses of displaced workers can generate arbitrarily large cost of business cycles even if the second moments of the distribution of individual income changes are constant over the cycle. Thus, the previous literature, which has either disregarded long-term earnings losses of displaced workers or dealt with them only indirectly using second-moment analysis, might have severely under-estimated the welfare cost of business cycles. In addition to the theoretical analysis, this paper also conducts a quantitative study of the cost of business cycles using empirical evidence on the long-term earnings losses of U.S. workers. The quantitative analysis suggests that cyclical variations in job displacement risk generate sizable cost of business cycles.
\end{abstract}

JEL Classification: E21, E32, E63, D52

Keywords: Macroeconomics, Cost of Business Cycles, Job Displacement Risk, Incomplete Markets

${ }^{*}$ I would like to thank seminar participants at Brown University, Maryland, MIT, UPenn, and the NBER Monetary Program Meeting, Fall 2004, for very useful comments. All remaining errors are mine.

${ }^{\dagger}$ Department of Economics, 64 Waterman Street, Providence, RI 02912. E-mail: tom_krebs@brown.edu 


\section{Introduction}

In a highly influential contribution, Lucas (1987) argues that standard macroeconomic theory implies that the welfare cost of business cycles is negligible. In other words, Lucas (1987) argues that from a welfare point of view, business cycle research and counter-cyclical stabilization policy are irrelevant. His argument is based on a representative-agent model with no production and "standard" preferences. More specifically, Lucas (1987) assumes that i) there is no uninsurable idiosyncratic risk (complete markets), ii) there is no link between business cycles and economic growth, and iii) preferences allow for a time-additive expected utility representation with moderate degree of (relative) risk aversion. In principle, any one of these three assumptions could be questioned, and an extensive literature has subsequently studied how weakening these assumptions could change the surprisingly strong conclusion drawn by Lucas (1987). In his recent survey, Lucas (2003) summarizes the findings of this literature in the following way: "But I argue in the end that, based what we know now, it is unrealistic to hope for gains larger than a tenth of a percent from better countercyclical policy".

This paper removes the complete-markets assumption made by Lucas (1987), and argues that the introduction of uninsurable idiosyncratic labor market risk (incomplete markets) generates substantial welfare costs of business cycles. In accordance with the previous literature, this paper takes as a starting point of the analysis the observation that idiosyncratic labor market risk has a cyclical component (labor income risk is high during recessions), and assumes that the elimination of business cycles leads to the elimination of the cyclical fluctuations in idiosyncratic labor market risk. In contrast to the previous literature, however, this paper broadens the scope of the analysis. More precisely, job displacement risk can increase during a recession for the following three reasons: i) an increase in the job displacement rate, ii) a rise in the unemployment duration, and iii) an increase in the long-term earnings losses 
of displaced workers ${ }^{1}$ The previous literature has either confined attention to i) and ii) or dealt with iii) only indirectly using a second-moment approach. In this paper, we study iii) and explicitly take into account that the second moment (variance) of log-income changes might be a bad measure of risk if job displacement is a rare event with severe consequences.

The paper presents two results, one theoretical and one empirical, that suggest that cyclical variations in the long-term earnings losses of displaced workers generate cost of business cycles that are substantially larger than the cost reported by the previous literature. First, this paper shows that for sufficiently high degree of risk aversion (at least one), the cost of business cycles can be arbitrarily large even if job displacement rates, unemployment durations, and the second moments of the distribution of individual income shocks are constant over the cycle. Intuitively, if the long-term earnings losses of displaced workers strongly increase during recessions, then the cost of business cycles might be very large even if the variance of the distribution of income changes is (almost) constant over the cycle. ${ }^{2}$ Thus, the previous literature, which has either neglected the long-term earnings losses of displaced workers or dealt with them only indirectly using second-moment analysis, may have severely under-estimated the cost of business cycles.

In addition to the theoretical analysis, this paper also provides a first quantitative analysis of the welfare effects of cyclical fluctuations in job displacement risk. More specifically, this paper uses evidence about job displacement rates and the long-term earnings losses of displaced U.S. workers obtained by the empirical literature to calibrate the model economy, and then computes the cost of business cycles for the calibrated version of the model. The

\footnotetext{
${ }^{1}$ See, for example, Blanchard and Diamond (1990) and Hall (1995) for empirical evidence on the cyclical behavior of job displacement rates and unemployment duration. See section IV.1. for a survey of the empircal literature on the long-term earnings losses of displaced workers.

${ }^{2}$ Krebs (2004) uses a similar idea to show that any arbitrage-free asset return process is an equilibrium outcome for given preferences and given process of first and second moments of individual income changes.
} 
quantitative analysis shows that cyclical fluctuations in job displacement risk generate sizable welfare cost of business cycles. For example, in the baseline economy with log-utility preferences (degree of risk aversion of one), the welfare cost of business cycles for high-tenure workers is around half a percentage point of lifetime consumption, and this cost increases to one percentage point if we assume a degree of relative risk aversion of two. In contrast, for the same economy with no cyclical fluctuations in the earnings losses of displaced workers, the welfare cost of business cycles is nil. Moreover, the implied cyclical variations in the second moments of the distribution of individual income shocks are so small that a log-normal view of the world would suggest negligible cost of business cycles.

At this stage, it is worth pointing out that the results reported here do not necessarily imply that macroeconomic stabilization policy leads to substantial welfare gains. For example, the current paper follows Lucas (1987) and disregards any link between short-run fluctuations in aggregate output (business cycles) and the mean of aggregate output (economic growth). ${ }^{3}$ Moreover, in accordance with the previous literature, this paper uses a "black-box" approach to the elimination of business cycles in the sense that it does not explicitly model the interaction between counter-cyclical stabilization policy and the business cycle. More specifically, this paper follows recent contributions to the literature (Krebs 2003a, Krusell and Smith, 1999, Lucas, 2003) and uses the "integration principle" in order to remove cyclical variations in idiosyncratic risk. For the specific case considered in this paper, the integration principle implies that cycle-dependent earnings losses are replaced by cycle-independent earnings losses with the same mean. Despite these limitations, the current analysis seems well-suited for addressing the issue that is the topic of Lucas (2003), namely

\footnotetext{
${ }^{3}$ For example, the elimination of business cycles might affect the aggregate stock of physical capital (Krusell and Smith, 1999) or human capital (Krebs, 2003a) in the economy. Moreover, business cycles affect the re-allocation of factors across heterogenous production units, which in turn affects aggregate economic growth. See, for example, Haltiwanger (2000) for a recent survey of the theoretical and empirical literature on the growth effects of factor re-allocation.
} 
whether our current theoretical and empirical knowledge suffices to rule out substantial welfare cost of business cycles. As shown in this paper, sizable cost of business cycles cannot be ruled out once we take into account the long-term earnings losses of displaced workers.

Finally, a comment regarding modeling strategy is in order. The objective of the current paper is to study the welfare effects of business cycles when workers face uninsurable job displacement risk. As it is well-known, equilibria of incomplete-market models with idiosyncratic risk and aggregate shocks are in general difficult to compute and (almost) impossible to analyze theoretically. In order to focus on the main economic issues, the analysis presented here is therefore based on a highly tractable incomplete-market model along the lines of Constantinides and Duffie (1996) and Krebs (2004). The model is simple enough to allow for the derivation of simple and transparent expressions for the welfare cost of business cycles, yet rich enough to establish a tight link between the theoretical earnings process and the empirical literature on job displacement risk. ${ }^{4}$

The paper is organized as follows. Section II surveys the previous literature. Section III develops the model that is used to discuss the effect of job displacement risk on the welfare cost of business cycles. Section IV derives a closed-form expression for the welfare cost of business cycles, and uses these expressions to prove the main theoretical result: cyclical fluctuations in job displacement risk may have an arbitrarily large effect on the cost of business cycles even if there is no employment risk and the second moments of the distribution of income shocks have no cyclical component (proposition 2). Section V provides an extensive review of the empirical literature on job displacement risk. The results of this

\footnotetext{
${ }^{4} \mathrm{An}$ alternative approach would be to use preferences and estimates of the process of individual consumption risk to derive the welfare cost of business cycles. Although in general quite attractive, such an approach has the drawback that the empirical literature on labor market risk has mainly focused on cyclical variations in individual income risk (for an important exception, see Brav, Constantinides, and Gescy, 2002). Put differently, we know much more about cyclical variations in individual income risk than we know about cyclical variations in individual consumption risk.
} 
literature are used to calibrate the process of job displacement risk, and the calibrated model economy is then used to analyze the quantitative effect of cyclical fluctuations in job displacement risk on the cost of business cycles. Section VI concludes.

\section{Previous Literature}

We now briefly survey the literature on the cost of business cycles in models with incomplete markets. Most of the previous literature has focused on quantitative results derived from analyzing calibrated model economies.

Atkeson and Phelan (1994), Imrohoroglu (1989), and Krusell and Smith (1999,2002) all study models of worker unemployment, and assume that cyclical fluctuations in unemployment rates and unemployment durations are the only sources of cyclical variations in idiosyncratic labor market risk, but assume that the earnings of displaced workers fully recover after re-employment at a new job. Thus, they rule out by assumption the type of effect studied here. Gomes, Greenwood, and Rebelo (2001) extent the analysis of unemployment risk and allow for endogenous search. In this case, business cycles may have a positive effect on welfare (option value of search). ${ }^{5}$

The papers by Gomes, Greenwood, and Rebelo (2001) and Krusell and Smith $(1999,2002)$ employ versions of the neoclassical model with aggregate productivity shocks that generate cyclical fluctuations in the aggregate wage, and in this sense these papers take into account cyclical fluctuations in the income losses of displaced workers. However, in the calibrated model economies considered by these authors, the cyclical fluctuations in the aggregate wage have relatively low persistence and small amplitude, and therefore do not generate sizable

\footnotetext{
${ }^{5}$ See also Manuelli, Jones, Siu, and Staccetti (2003) and Jovanovic (2003) for representative-agent models in which aggregate fluctuations have a positive effect on growth.
} 
cost of business cycles. ${ }^{6}$ Beaudry and DiNardo (2001) consider a model of unemployment in which the wage of new hires varies over the business cycle, and argue that these cyclical variations are much more persistent and stronger than the cyclical variations in the aggregate wage. In this sense, the analysis conducted in Beaudry and DiNardo (2001) is closely related to the current analysis. However, in contrast to Lucas (2003) and most of the work in the literature, Beaudry and Page (2001) simply assume that the elimination of business cycles eliminates all idiosyncratic risk, and this assumption makes it difficult to judge to what extent the welfare cost reported in Beaudry and Pages (2001) are truly cost of business cycle.

Krebs (2003a) and Storesletten, Telmer, and Yaron (2001) discuss the cost of business cycles when individual income shocks are (log)-normally distributed and the variance of these shocks depend on business cycle conditions, but they do not condition on the job displacement event. According to the model analyzed in this paper, log-income changes are only normally distributed after we condition on the individual job displacement event (and business cycles conditions). In a certain sense, the models considered by Krebs (2003a) and Storesletten et al. (2001) are mis-specified. The subsequent analysis will show that this type of mis-specification can lead to a serious under-estimate of the cost of business cycles (proposition 3$).^{7}$

Finally, Krebs (2003b) and Rogerson and Schindler (2002) study the welfare cost of job displacement risk and also focus on the income losses of displaced workers. However, Krebs (2003b) and Rogerson and Schindler (2002) analyze the welfare gain from eliminating job displacement risk in an economy with constant job displacement risk, whereas the current paper studies the welfare gains from eliminating the cyclical variations in job displacement

\footnotetext{
${ }^{6}$ Similarly, the cyclical fluctuations in unemployment durations considered by these authors introduce cyclical variations in the income losses of displaced workers.

${ }^{7}$ Comment that results have changed.
} 
risk (keeping average job displacement risk constant).

\section{Model}

The model is an incomplete-market version of the Lucas asset pricing model (Lucas, 1978) similar to the one considered in Constantinides and Duffie (1996) and Krebs (2004). ${ }^{8}$ It provides a formal approach to the intuitive idea that consumption equals permanent income. The model features ex-ante identical, long-lived households (workers) with homothetic preferences that make consumption/saving choices in the face of uninsurable income shocks. Income shocks are permanent, which implies that self-insurance is an ineffective means to smooth out income fluctuations. Indeed, the economy is set up in a way so that in equilibrium households will not self-insure at all. That is, income shocks translate one-to-one into consumption changes (proposition 1). Notice that the result that permanent income shocks have large effects on consumption does not depend on the assumption that aggregate saving is zero, even though we will make it to simplify the analysis. For example, Krebs $(2003 \mathrm{a}, 2003 \mathrm{~b})$ considers a production economy with only permanent income shocks (log-income follows a random walk) and ex-ante identical households, and shows again that self-insurance is highly ineffective. ${ }^{9}$ Deaton (1991) and Carroll (1997) provide a partial equilibrium analysis of the effect of permanent income shocks on consumption and saving, and also conclude that the main effect of permanent income shocks is to change consumption.

\footnotetext{
${ }^{8}$ To simplify the analysis, the current paper does not allow for assets in positive net supply. See Constantinides and Duffie (1996) and Krebs (2004) for an extension of the model to this case. In the appendix, we also consider a version of the model with two groups of workers (low- and high-tenure workers) who face different degrees of job displacement risk.

${ }^{9}$ One implication of the random walk assumption is that the cross-sectional distributions of income and consumption diverge. However, Constantinides and Duffie (1996) show how to modify the model by introducing death probabilities so that a stationary distribution of income and consumption always exists. Indeed, they show that by choosing the death probabilities appropriately, the model can match any crosssectional distribution of income and consumption.
} 
There is strong empirical evidence that individual labor income risk has a substantial permanent (or highly persistent) component, ${ }^{10}$ and the empirical estimates of this permanent component will be used in the quantitative section (section IV) to calibrate the model economy. The same empirical literature also provides clear evidence in favor of a substantial transitory component of labor income risk, and in this sense the current model is not consistent with a certain dimension of the data. More specifically, the job displacement event has two effects on the earnings of a displaced worker. First, the worker goes through a period of unemployment with no earnings (the transitory effect). Second, the worker finds a new job, but receives a permanently lower wage (the permanent effect). In the current paper, we disregard the first effect, and only focus on the second effect. Given that the first effect has been extensively studied by the previous literature (Atkeson and Phelan (1994), Imrohoroglu (1989), Krusell and Smith (1999,2002)), this modeling choice seems appropriate.

\section{III.1. Economy}

Time is discrete and open ended. Labor income of worker $i$ in period $t$ is denoted by $y_{i t}$. Labor income is random and defined by an initial level $y_{i 0}$ and the law of motion

$$
y_{i, t+1}=(1+g)\left(1+\theta_{i, t+1}\right)\left(1+\eta_{i, t+1}\right) y_{i t}
$$

where $g$ is the (constant) aggregate growth rate of labor income and $\theta_{i, t+1}$ and $\eta_{i, t+1}$ describe shocks to the labor income of worker $i{ }^{11}$ We assume that for each $i$ and $t$, the two random variable $\theta_{i, t+1}$ and $\eta_{i, t+1}$ are independently distributed. Further, we assume that the sequence of random variables $\left\{\theta_{i t}\right\}$ is i.i.d. across workers and over time with log-normal distribution

\footnotetext{
${ }^{10}$ See, for example, Carroll and Samwick (1997), Jacobson, LaLonde, and Sullivan (1993), Meghir and Pistaferri (2004), Ruhm (1991), and Storesletten, Telmer, and Yaron (2004).

${ }^{11}$ Notice that we do not allow the growth rate $g$ to vary over the business cycle. Thus, any welfare cost of business cycles reported here are solely due to cyclical variations in idiosyncratic labor market risk.
} 
function: ${ }^{12}$

$$
\log \left(1+\theta_{i, t+1}\right) \sim N\left(-\sigma^{2} / 2, \sigma^{2}\right) .
$$

The sequence of random variables $\left\{\eta_{i t}\right\}$ is also i.i.d. across workers, but not over time. More specifically, we assume that there is an aggregate state process $\left\{S_{t}\right\}$ that is i.i.d., and that the distribution of $\eta_{i t}$ depends on the aggregate state of the economy in the following way:

$$
\eta_{i, t+1}=\left\{\begin{array}{lll}
-d_{S} & \text { with probability } & p_{S} \text { if } S_{t+1}=S \\
\frac{p_{S} d_{S}}{1-p_{S}} & \text { with probability }\left(1-p_{S}\right) \text { if } S_{t+1}=S
\end{array}\right.
$$

The random variable $\eta_{i t}$ is the cyclical component of labor income risk, and we interpret this component as describing job displacement risk. The number $d_{S}$ is the (permanent) income loss of a worker who is displaced when the aggregate state is $S$, and the number $p_{S}$ is the corresponding displacement probability. For simplicity, we have assumed that all displaced workers experience the same income loss $d_{S}$. However, our analysis remains unchanged if we assume that the income losses of displaced workers are log-normally distributed with mean $d_{S}$ and constant variance since this formulation is observationally equivalent to the current formulation. Notice that we have also assumed that the worker gains income $\frac{p_{S}}{1-p_{S}} d_{S}$ if he is not displaced in order to ensure that the random variable $\eta_{i t}$ has mean zero. Finally, the i.i.d. assumption means that income changes associated with the displacement event are unpredictable, which implies that the corresponding income losses are permanent. The income losses of displaced workers, and in particular its permanent component, have been extensively studied by the empirical literature (Faber (1997), Jacobson, LaLonde, and Sullivan (1993), Neal (1995), Ruhm (1991), Topel (1991)). Notice also that the specification (3) allows the size of the income loss of displaced workers to have a cyclical component $\left(d_{S}\right.$

\footnotetext{
${ }^{12}$ Note that it is standard in the literature (Carroll (1997), Constantinides and Duffie (1996), and Storesletten, Telmer, and Yaron (2001)) to introduce the extra term $-\sigma^{2} / 2$, which ensures that the mean of income growth is independent of $\sigma^{2}$. More precisely, specification (2) implies that $E\left[\theta_{i, t+1}\right]=0$ and $\operatorname{var}\left[\theta_{i, t+1}\right]=e^{\sigma^{2}}-1$ using the standard formula for log-normal distributions. Thus, any increase in $\sigma^{2}$ increases $\operatorname{var}\left[\theta_{i, t+1}\right]$, but leaves $E\left[\theta_{i, t+1}\right]$ unchanged.
} 
depends on $S$ ), something that finds support in the data (Jacobson, LaLonde, and Sullivan (1993)), and is particularly important from the point of view of the current paper. In section $\mathrm{V}$ we will discuss the empirical literature on job displacement risk in more detail, and use the estimates of job displacement risk obtained by this literature to calibrate the model economy.

The random variable $\theta_{i t}$ is the a-cyclical component of labor income risk, and we interpret it as containing any labor income risk beyond job displacement risk. To relate this variable to the empirical literature, let us take logs in equation (1):

$$
\log y_{i, t+1}=\log y_{i t}+\log (1+g)+\log \left(1+\theta_{i, t+1}\right)+\log \left(1+\eta_{i, t+1}\right)
$$

Equation (4) says log-labor income approximately follows a random walk with drift and heteroscedastic error term $\epsilon_{i, t+1}=\log \left(1+\theta_{i, t+1}\right)+\log \left(1+\eta_{i, t+1}\right)$, which is yet another way of saying that income shocks are permanent. An extensive empirical literature has estimated the parameters of the permanent component of income shocks under the log-normal distribution assumption ${ }^{13}$ and the estimates obtained by this literature can be used to find a value of $\operatorname{var}\left(\left(\log y_{i, t+1}-\log y_{i t}\right)\right)$, and therefore indirectly a value for $\operatorname{var}\left(\log \left(1+\theta_{i, t+1}\right)\right)=\sigma^{2}$ in $(2)$. Notice, however, that even though two recent contributions by Meghir and Pistaferri (2004) and Storesletten et al. (2004) have allowed the variance of log-income changes to depend on the aggregate state $S$, this literature (in contrast to the literature on job displacement mentioned above) has not conditioned their estimates on the displacement event and has not taken into account any deviations from the log-normal distribution assumption. ${ }^{14}$ Clearly, if

\footnotetext{
${ }^{13}$ See, for example, Carroll and Samwick (1997), Meghir and Pistaferri (2004), and Storesletten, et al. (2004). Notice that even though Storesletten, et al. (2004) specify the permanent component to be AR(1), they estimate an autocorrelation coefficient close to one (the random walk case).

${ }^{14}$ Geweke and Keane (2000) allow for deviations from the log-normal distribution assumption. In contrast to Meghir and Pistaferri (2004) and Storesletten et al. (2004), however, they do not condition their estimates of the labor income parameters on the aggregate state of the economy and they do not decompose labor income risk into a transitory and a permanent component.
} 
the specification (4) is correct, then the error term $\epsilon_{i, t+1}=\log \left(1+\theta_{i, t+1}\right)+\log \left(1+\eta_{i, t+1}\right)$ is not normally distributed (indeed, it is the mixture of two normal distributions with different means), which implies that one of the identifying assumptions of this literature is violated.

Each worker begins life with no initial financial wealth. Workers have the opportunity to borrow and lend (dissave and save) at the risk-free rate $r_{t}$. There are no insurance markets for idiosyncratic labor income risk. In other words, there are no assets with payoffs that, conditional on the aggregate state $S$, are correlated with either $\theta_{i t}$ or $\eta_{i t}$. Thus, the sequential budget constraint of worker $i$ reads: ${ }^{15}$

$$
\begin{aligned}
& a_{i, t+1}=\left(1+r_{t}\right) a_{i t}+y_{i t}-c_{i t} \\
& a_{i, t+1} \geq-M, a_{i 0}=0 .
\end{aligned}
$$

Here $c_{i t}$ denotes consumption of household $i$ in period $t$ and $a_{i t}$ his asset holdings (wealth excluding current interest payments) at the beginning of period $t$. The real number $M$ represents an explicit debt constraint that rules out Ponzi schemes.

Workers have identical preferences that allow for a time-additive expected utility representation:

$$
U\left(\left\{c_{i t}\right\}\right)=E\left[\sum_{t=0}^{\infty} \beta^{t} u\left(c_{i t}\right)\right] .
$$

Moreover, we assume that the one-period utility function, $u$, is given by $u(c)=\frac{c^{1-\gamma}}{1-\gamma}$, for $\gamma \neq 1$ and $u(c)=\log c$ for $\gamma=1$. That is, we assume that preferences exhibit constant degree of relative risk aversion $\gamma$.

Finally, we assume that the following condition is satisfied:

$$
\beta E\left[\left((1+g)^{1-\gamma}\left(1+\theta_{i, t+1}\right)\left(1+\eta_{i, t+1}\right)\right)^{1-\gamma}\right]
$$

\footnotetext{
${ }^{15}$ Notice that the analysis remains unchanged if we assume that agents have the opportunity to trade assets whose payoffs depend on the aggregate state $S$ (Krebs, 2004). Our assumption that there are no insurance markets means that one should interpret $y_{i t}$ as income after transfer payments from the government.
} 


$$
\begin{aligned}
& =\beta(1+g)^{1-\gamma} e^{\frac{1}{2} \gamma(\gamma-1) \sigma^{2}} \sum_{S} \pi_{S}\left(p_{S}\left(1-d_{S}\right)^{1-\gamma}+\left(1-p_{S}\right)\left(1+\frac{p_{S} d_{S}}{1-p_{S}}\right)^{1-\gamma}\right), \\
& <1
\end{aligned}
$$

where $\pi_{S}$ is the probability that aggregate state $S$ occurs. This inequality will ensure that in equilibrium the expected lifetime utility of workers is finite for any budget-feasible plan, and that any solution to the Euler equation also solves a corresponding transversality condition. Notice that this condition is automatically satisfied if $\gamma=1$ (log-utility).

\section{III.2. Equilibrium}

For a given interest rate process $\left\{r_{t}\right\}$, each household chooses a consumption-saving plan that maximizes expected lifetime utility (6) subject to the budget constraint (5). In equilibrium, the asset (bond) market must clear. In an exchange economy, this means aggregate saving is zero: ${ }^{16}$

$$
\sum_{i} a_{i t}=0
$$

Notice that (5) and (8) imply goods market clearing (Walras' law).

The Euler equations associated with the consumption-saving problem of worker $i$ read

$$
c_{i t}^{-\gamma}=\beta\left(1+r_{t+1}\right) E\left[c_{i, t+1}^{-\gamma} \mid F_{i t}\right]
$$

where $F_{i t}$ represents the information that is available to household $i$ in period $t$. In the following, we assume that $F_{i t}$ contains any variable that has been realized up to time $t$. In particular, it contains $\theta_{i t}, \eta_{i t}$, and $S_{t}$. The Euler equation (9) says that the marginal utility cost of saving one more unit of the good is equal to the expected marginal utility gain of doing so.

\footnotetext{
${ }^{16}$ The notation suggests that there are a finite number of households, but all propositions in this paper remain valid for the case of a continuum of households.
} 
Suppose the interest rate is constant and given by:

$$
1+r=\left(\beta E\left[\left(\frac{y_{i, t+1}}{y_{i t}}\right)^{-\gamma}\right]\right)^{-1}
$$

Evaluating the expectations in (10) using (2) and (3) yields:

$$
r=\left(\beta(1+g)^{-\gamma} e^{\frac{1}{2} \gamma(\gamma+1) \sigma^{2}} \sum_{S} \pi_{S}\left[p_{S}\left(1-d_{S}\right)^{-\gamma}+\left(1-p_{S}\right)\left(1+\frac{p_{S} d_{S}}{1-p_{S}}\right)^{-\gamma}\right]\right)^{-1} .
$$

Given this interest rate, the Euler equation (9) is satisfied if workers consume all their income: $c_{i t}=y_{i t} .{ }^{17}$ If $c_{i t}=y_{i t}$, then $a_{i t}=0$ (budget constraint). In Krebs (2004) it is shown that the consumption-saving plan $c_{i t}=y_{i t}$ and $a_{i t}=0$ also satisfies a corresponding transversality condition if the interest rate is given by (11). Thus, it maximizes expected lifetime utility. Clearly, the choice $a_{i t}=0$ also satisfies the market clearing condition (8). Thus, we have found an equilibrium.

The result that equilibrium consumption equals income, $c_{i t}=y_{i t}$, means that equilibrium welfare (expected lifetime utility), $U$, is given by:

$$
U \doteq E\left[\sum_{t=0}^{\infty} \beta^{t} u\left(c_{i t}\right)\right]=E\left[\sum_{t=0}^{\infty} \beta^{t} u\left(y_{i t}\right)\right]
$$

Using the preference specification (6) and the definition of the income process (1)-(3), direct calculation yields the following formula for equilibrium welfare:

$$
\begin{aligned}
U & =\frac{y_{i 0}^{1-\gamma}}{(1-\gamma)\left(1-\beta E\left[\left((1+g)^{1-\gamma}\left(1+\theta_{i}\right)\left(1+\eta_{i}\right)\right)^{1-\gamma}\right]\right)} \quad \text { if } \gamma \neq 1 \\
U & =\frac{1}{1-\beta} \log y_{i 0}+\frac{\beta}{(1-\beta)^{2}} E\left[\log \left((1+g)\left(1+\theta_{i}\right)\left(1+\eta_{i}\right)\right)\right] \quad \text { if } \gamma=1 .
\end{aligned}
$$

Using the distributional assumption (2) and (3), we can evaluate the expectations in (13)

\footnotetext{
${ }^{17}$ Notice that here we use the fact that $\theta_{i t}$ and $\eta_{i t}$ do not predict future idiosyncratic shocks to income. That is, we have used the fact that $\left(\theta_{i t}, \eta_{i t}\right)$ and $\left(\theta_{i, t+1}, \eta_{i, t+1}\right)$ are uncorrelated. Without this assumption, the Euler equation (9) would not hold at $a_{i t}=0$ and $c_{i t}=y_{i t}$ for the interest rate (10).
} 
and find:

$$
\begin{aligned}
U & =\frac{y_{i 0}^{1-\gamma}}{(1-\gamma)\left(1-\beta(1+g)^{1-\gamma} e^{\frac{1}{2} \gamma(\gamma-1) \sigma^{2} / 2} \sum_{S} \pi_{S}\left[p_{S}\left(1-d_{S}\right)^{1-\gamma}+\left(1-p_{S}\right)\left(1-\frac{p_{S} d_{S}}{1-p_{S}}\right)^{1-\gamma}\right]\right)} \\
U & =\frac{1}{1-\beta} \log y_{i 0} \\
& +\frac{\beta}{(1-\beta)^{2}}\left(\log (1+g)-\sigma^{2} / 2+\sum_{S} \pi_{S}\left[p_{S} \log \left(1-d_{S}\right)+\left(1-p_{S}\right) \log \left(1+p_{S} d_{S} /\left(1-p_{S}\right)\right)\right]\right) .
\end{aligned}
$$

We summarize the preceding discussion in the following proposition:

Proposition 1. The consumption-saving plan $\left\{a_{i t}, c_{i t}\right\}$, where $a_{i t}=0$ and $c_{i t}=y_{i t}$, in conjunction with the interest rate process (9) constitute an equilibrium. Welfare (expected lifetime utility) of workers in this equilibrium is given by (13), respectively (14).

\section{Cost of Business Cycles: Qualitative Analysis}

In this section, we use the model laid out in section III to derive an explicit formula for the welfare cost of business cycles (proposition 2). Using this welfare expression, we then show the main theoretical result, namely that the cost of business cycles might be arbitrarily large even if the second moments of the distribution of individual income changes are constant over the business cycle (proposition 3). Indeed, the result we prove here is somewhat stronger in the sense that our proof assumes that job displacement probabilities are constant over the cycle. In other words, cyclical fluctuations in the earnings losses of displaced workers are sufficient to prove the result.

\section{IV.1. Eliminating Business Cycles}

We begin this section with a discussion of how the elimination of business cycles affects the nature of idiosyncratic risk. In our model, the elimination of business cycles amounts to moving from an economy with fluctuations in the aggregate state $S$ (the economy with 
business cycles) to an economy with constant $S$ (the economy without business cycles). In other words, we are moving from an economy with income risk defined by the $S$-independent distribution of income shocks $\theta_{i}$ and $S$-dependent distribution of income shocks $\eta_{i}$ to an economy with income risk defined by the $S$-independent distributions of income shocks $\bar{\theta}_{i}$ and $\bar{\eta}_{i}$. The question that arises is how to find the distributions of $\bar{\theta}_{i}$ and $\bar{\eta}_{i}$ given the distributions of $\theta_{i}$ and $\eta_{i}$. Following Lucas (1987) and the subsequent literature, we will answer this question without an explicit model of the interaction between macroeconomic stabilization policy and the business cycle.

For economies without uninsurable idiosyncratic risk (complete markets), Lucas (1987) postulates that the elimination of business cycles amounts to replacing all $S$-dependent economic variables by their mean value. That is, we take the expectations over $S$. Extending this approach to economies with uninsurable idiosyncratic risk (incomplete markets), we postulate that eliminating business cycles means that we replace all $S$-dependent economic variables by their expected value with respect to $S$ conditional on the idiosyncratic state of an individual worker. This "integration principle" has been used by several previous authors (Krebs (2003a), Krusell and Smith (1999,2002), and Lucas (2003)). For economic variables that have no $S$-dependence, the integration principle implies that the elimination of business cycles has no effect. Thus, for the a-cyclical component of individual income shocks we have $\bar{\theta}_{i}=\theta_{i}$, and therefore

$$
\log \left(1+\bar{\theta}_{i}\right) \sim N\left(-\sigma^{2} / 2, \sigma^{2}\right)
$$

For the cyclical component of income shocks, $\eta_{i}$, the integration principle reads:

$$
\bar{\eta}_{i}=E\left[\eta_{i} \mid s_{i}\right]
$$

where $s_{i}=0$ if worker $i$ is not displaced and $s_{i}=1$ if worker $i$ is displaced. Taking the expectations in (16) yields:

$$
\bar{\eta}_{i}=\left\{\begin{array}{c}
-\bar{d} \text { with probability } \bar{p} \\
\frac{\bar{p} \bar{d}}{1-\bar{p}} \text { with probability }(1-\bar{p})
\end{array},\right.
$$


where displacement rates and earnings losses in the economy without business cycles are given by

$$
\begin{aligned}
\bar{p} & =\sum_{S} \pi_{S} p_{S} \\
\bar{d} & =\sum_{S} \frac{\pi_{S} p_{S}}{\bar{p}} d_{S} .
\end{aligned}
$$

Equation (17) and (18) show that the application of the integration principle (16) to the current model requires that we use the conditional probabilities $\operatorname{prob}\left(S \mid s_{i}=1\right)=\frac{p_{S}}{\bar{p}} \pi_{S}$ to calculate the expected value of the income losses $d_{S}$. Alternatively, we could use the unconditional probabilities $\pi_{S}$, that is, we could replace (18) by

$$
\begin{aligned}
\bar{p} & =\sum_{S} \pi_{S} p_{S} \\
\bar{d} & =\sum_{S} \pi_{S} d_{S} .
\end{aligned}
$$

Equation (19) seems plausible if the earnings losses $d$ are a linear function of aggregate GDP (growth), and if, as in Lucas (1987), we assume that the elimination of business cycles amount to replacing stochastic GDP (growth) by its (unconditional) mean. Notice that (18) and (19) are only the same if job displacement rates are constant: $p_{S}=\bar{p}$. However, even in cases in which (18) and (19) differ from each other, it turns out that the main theoretical results derived in this paper (proposition 2 and 3 below) are valid regardless of the choice that we make. In contrast, the quantitative results will be affected. Since both (18) and (19) seem plausible, in section $\mathrm{V}$ we report all quantitative welfare results for both cases.

\section{IV.2. Cost of Business Cycles}

Equations (18), respectively (19), shows how the elimination of business cycles affect the labor income process. We can use this information in conjunction with our welfare formula (13) to calculate the welfare cost of business cycles. More precisely, we define the welfare 
cost of business cycles as the number $\Delta$ that solves

$$
E_{0}\left[\sum_{t=0}^{\infty} \beta^{t} u\left(c_{i t}(1+\Delta)\right)\right]=E_{0}\left[\sum_{t=0}^{\infty} \beta^{t} u\left(\bar{c}_{i t}\right)\right],
$$

where $c_{i t}$ is consumption in the economy with business cycles and $\bar{c}_{i t}$ is consumption in the economy without business cycles. That is, we define the welfare cost of business cycles as the percentage of consumption in each date-event that workers have to receive in order to be fully compensated for the cyclical variations in labor income risk. Using the definition (20) in conjunction with the welfare formula (13), we find the following formula for the cost of business cycles:

$$
\begin{aligned}
\Delta & =\left(\frac{1-\beta(1+g)^{1-\gamma} E\left[\left(1+\theta_{i}\right)^{1-\gamma}\left(1+\eta_{i}\right)^{1-\gamma}\right]}{1-\beta(1+g)^{1-\gamma} E\left[\left(1+\theta_{i}\right)^{1-\gamma}\left(1+\bar{\eta}_{i}\right)^{1-\gamma}\right]}\right)^{\frac{1}{1-\gamma}}-1 \quad \text { if } \gamma \neq 1 \\
\Delta & =\frac{\beta}{1-\beta}\left(E\left[\log \left(1+\bar{\eta}_{i}\right)\right]-E\left[\log \left(1+\eta_{i}\right)\right]\right) \quad \text { if } \gamma=1 .
\end{aligned}
$$

Using (14), we can evaluate the expectations in (22) and find:

$$
\begin{aligned}
\Delta & =\left(\frac{1-\beta(1+g)^{1-\gamma} e^{\frac{1}{2} \gamma(\gamma-1) \sigma^{2}} \sum_{S} \pi_{S}\left[p_{S}\left(1-d_{S}\right)^{1-\gamma}+\left(1-p_{S}\right)\left(1+\frac{p_{S} d_{S}}{1-p_{S}}\right)^{1-\gamma}\right]}{1-\beta(1+g)^{1-\gamma} e^{\frac{1}{2} \gamma(\gamma-1) \sigma^{2}}\left[\bar{p}(1-\bar{d})^{1-\gamma}+(1-\bar{p})\left(1+\frac{\bar{p} \bar{d}}{1-\bar{p}}\right)^{1-\gamma}\right]}\right)^{\frac{1}{1-\gamma}}-1 \\
\Delta & =\frac{\beta}{1-\beta}(\bar{p} \log (1-\bar{d})+(1-\bar{p}) \log (1+\bar{p} \bar{d} /(1-\bar{p})) \\
& -\frac{\beta}{1-\beta}\left(\sum_{S} \pi_{S}\left[p_{S} \log \left(1-d_{S}\right)+\left(1-p_{S}\right) \log \left(1+p_{S} d_{S} /\left(1-p_{S}\right)\right)\right]\right)
\end{aligned}
$$

Several facts about (22) are noteworthy. First, the cost of business cycles is the same for all worker. This is a result of the joint assumption of homothetic preferences and permanent income shocks with a distribution that is independent of workers' characteristics. Second, if we use equation (18) to eliminate business cycles, then the welfare cost of business cycles is non-negative: $\Delta \geq 0$. This fact immediately follows from the concavity of the utility function in conjunction with the fact that $\eta_{i}$ is a mean-preserving spread of $\bar{\eta}_{i}$. Thus, cyclical variations in idiosyncratic labor income risk never decrease the welfare cost of business cycles. 
If $p_{S}$ and $d_{S}$ are positively correlated, then one can show that the same result holds even if we use (19) to eliminate business cycles. Moreover, and more importantly, regardless of which of the two methods is chose to eliminate business cycles, the cost of business cycles is nil, $\Delta=0$, if the income losses of displaced workers are constant: $d_{S}=\bar{d}$ for all aggregate states $S$. This last result immediately follows from the welfare expression (22) using either (18) or (19). Thus, if the only source of cyclical fluctuations in labor income risk is state-dependent displacement probabilities, then the introduction of uninsurable idiosyncratic labor market risk does not change the cost of business cycles. Similar neutrality results have been derived in Atkeson and Phelan (1994) and Krebs (2003a).

Proposition 2. The welfare cost of business cycles is given by (22). The cost of business cycles is nil, $\Delta=0$, if income losses of displaced workers have no cyclical component: $d_{S}=\bar{d}$ for all aggregate states $S$. That is, cyclical fluctuations in job displacement probabilities by themselves do not generate cost of business cycles.

Proposition 2 shows that there is not much hope for generating cost of business cycles through cyclical variations in job displacement probabilities only. Matters are different, however, once we allow for cyclical variations in the income losses of displaced workers: $d_{S} \neq d_{S^{\prime}}$ for some pair of aggregate states $S \neq S^{\prime}$. Inspection of $(22)$ suggests that we have $\Delta \rightarrow \infty$ when $d_{S} \rightarrow 1$ for some $S$ if $\gamma \geq 1$. That is, for high enough degree of risk aversion, the cost of business cycles becomes arbitrarily large when the income losses of displaced workers during certain macroeconomic conditions (recessions) become arbitrarily large. In the appendix, we show that this result still holds even if job displacement rates and the second moments of the distribution of income changes are (almost) constant. The trick here is to send simultaneously the displacement probability to zero, $p \rightarrow 0$, and to do this in a way so that the cost of business cycles is still growing without bounds, but the second moments of the distribution of income shocks is (almost) not affected. In short, we have the 
following proposition:

Proposition 3. Suppose the degree of relative risk aversion is large enough: $\gamma \geq 1$. Then there is a process of job displacement risk with constant job displacement rates so that i) the cost of business cycles is arbitrarily large and ii) the second moments of the distribution of individual income shocks are (almost) constant over the business cycle. More precisely, denote the second moment of the distribution of individual income shocks by $\operatorname{var}\left(y_{i, t+1} / y_{i t} \mid S_{t+1}\right)=\sigma_{y}^{2}\left(S_{t+1}\right)$ and assume $\gamma \geq 1 .{ }^{18}$ For any real numbers $\epsilon>0$ and $\bar{\Delta}>0$, we can find a process of job displacement risk with $p_{S}=p$ so that i) the implied cost of business cycles is $\Delta=\bar{\Delta}$ and ii) the implied second moments of the distribution of income shocks satisfy $\left|\sigma_{y}^{2}(S)-\sigma_{y}^{2}\left(S^{\prime}\right)\right|<\epsilon$ for all $S, S^{\prime}$.

\section{Cost of Business Cycles: Quantitative Analysis}

In this section, we analyze the quantitative importance of the main theoretical result derived in the previous section (proposition 3). To this end, we first discuss the calibration of the model economy (section V.1), and then report the quantitative results (section V.2). The economy we consider in this quantitative part is an extension of the basic model discussed and analyzed in sections III and IV. It features two types of workers, high-tenure and lowtenure workers (low- and high-risk workers), who face different degrees of job displacement risk. The details of the theoretical model with two types of workers are discussed in the Appendix.

\section{V.1. Calibration}

Following the previous literature (Imrohoroglu, 1989, Krebs, 2003a, Krusell and Smith,

\footnotetext{
${ }^{18}$ The proposition still holds if we consider the variance of log-income changes, $\sigma_{\text {logy }}^{2} \doteq$ $\operatorname{var}\left(\log y_{i, t+1}-\log y_{i t} \mid S_{t+1}\right)$, but for this version of proposition 3 the conditions $\gamma>1$ is required.
} 
1999, and Storesletten et al., 2001) we assume now that there are two aggregate states, $S=L, H$, corresponding to low economic activity (economic contraction) and high economic activity (economic expansion). We further follow the literature and disregard any asymmetry in the business cycle, that is, we assume that on average both aggregate states have the same likelihood of occurences. In our setting without persistence in the aggregate state process, this means that $\pi_{L}=\pi_{H}=.5$. We choose the period length to be one year to be consistent with the empirical work on labor market risk (see below). Thus, the choice of $\pi_{L}=\pi_{H}=.5$ implies an average duration of both good and bad times of two years, which is also the value considered in Imrohoroglu (1989), Krebs (2003a), and Krusell and Smith (1999,2002). We choose an average growth rate of labor income of $g=.02$.

For the model with two types of workers (the appendix), the process of job displacement risk is defined by the parameters $p_{s S}$ and $d_{s S}$, where $S=L, H$ (economic contraction and economic expansion) and $s=l, h$ (low- and high-tenure workers). We choose these parameters so that the model economy matches the first and second moments of the job displacement rate and the permanent earnings losses of corresponding group of U.S. displaced workers that have been estimated by the empirical literature. That is, we try to match previous estimates of i) the average probability of job displacement, ii) the cyclical variations of the job displacement probabilities, iii) the average permanent earnings loss of displaced workers, and iv) the cyclical variations in the permanent income loss of displaced workers. We now turn to a discussion of the estimates of these moments by the empirical literature.

\section{Earnings Losses of Displaced Workers}

There are many studies of the long-term consequences of job displacement for U.S. workers. One of the most detailed studies is Jacobsen et al. (1993), who use longitudinal data on the earnings of high-tenure workers (workers with at least six years of tenure) in Pennsylvania from 1974 to 1986 to estimate the earnings losses of displaced workers. In their restricted 
sample, they confine attention to workers that are separated from distressed firms, where they define a distressed firm as a firm that experienced an employment contraction of at least $30 \%$. For these workers, they find a very large drop in earnings the year following the displacement event (around 50\%). Moreover, and more importantly from the point of view of the current paper, these income losses have a sizable component that is highly persistent. More specifically, even 6 years after separation the earnings of the displaced workers is $25 \%$ below the earnings of workers with similar characteristics that have not been displaced. ${ }^{19}$ The result that high-tenure, displaced workers experience a permanent earnings loss of about $25 \%$ is also consistent with other estimates in the empirical literature. For example, Topel (1990) analyzes individual earnings data from the Panel Study of Income Dynamics (PSID) and estimates that displaced workers with at least 10 years of seniority prior to displacement suffer a permanent income loss of 25\%. ${ }^{20}$ In a similar vein, Kambourov and Manovskii (2002) find that ten years of occupational tenure increase wages by at least 19 percent.

Ruhm (1991) is another well-known study of the earnings losses of displaced workers. He uses PSID data to estimate these losses, and finds that the long-term earnings losses are substantial $(10-13 \%)$, but significantly lower than the $25 \%$ found by Jacobson et al. (1993). Clearly, the two studies rely on different data sets, and this could be one reason for the difference in results. However, it is more likely that the divergence in results is mainly driven by the fact that Jacobson et al (1993) confine attention to high-tenure workers, whereas

\footnotetext{
${ }^{19}$ Jacobson et al. (1993) also consider a larger sample of workers that consists of all separated workers including those who quit their job and those who get laid off due to "slack work". For workers who quit, we expect smaller earnings losses than before, and for workers who are laid off because of "slack work", we would expect higher earnings losses (Gibbon and Katz, 1991). Jacobson et al (1993) find that the average earnings losses of all separated workers are smaller than the earnings losses of workers that are displaced because of mass lay-offs, which suggest that the "quit-effect" dominates.

${ }^{20}$ Topel (1990) and others in the literature interpret these results as a confirmation of a human capital theory in which workers invest in firm-specific human capital, but recent work suggest that these losses are mainly due to the destruction of industry-specific (Neal, 1995) or occupation-specific (Kambourov and Manovskii, 2002) human capital. For a theoretical model of job separation with match-specific human capital, see Jovanovic (1979).
} 
Ruhm (1991) does not split his sample. Clearly, any theory of match-specific or occupation/industry-specific human capital would suggest that high-tenure workers experience large earnings losses upon displacement. This implication finds support in the study by Stevens (1997), who finds significant and large difference between the earnings losses of low- and high-tenure workers. However, even though there is a stark difference between the earnings losses of the two types of workers, it seems to be the case that even low-tenure workers experience substantial long-term losses as a result of job displacement. For example, Lorie and Farlie (2003) report that the young adult workers with only three years of labor market experience suffer a permanent earnings loss of around 10 percent, a loss that is mainly due to forgone earnings growth. Finally, we note that Farber (1997) uses evidence from the Displaced Workers Survey (DWS) and estimates earnings losses of around 15 percent for a sample that again includes both types of workers.

Based on the results described above, we choose a value of $25 \%$ for the average earnings losses of hight-tenure workers. That is, we choose the parameters $d_{h L}$ and $d_{h H}$ so that the restriction $.5 d_{h L}+.5 d_{h H}=.25$ is satisfied. Notice that both Krebs (2003b) and Rogerson and Schindler (2002) use a similar value in their studies of the welfare consequences of job displacement risk. For low-tenure workers, we assume an average earnings loss of 12\%, which yields $.5 d_{l L}=.5 d_{l H}=.12 \%$.

Another important issue is the degree to which the long-term earnings losses of displaced workers depend on cyclical conditions. Jacobson et al (1993) find strong evidence in favor of the view that these earnings losses vary over the business cycle, again for their sample of high-tenure workers. More specifically, they define the cyclical labor market condition by the unemployment rate and the deviation from trend employment, and estimate that workers who become displaced during the worst cyclical conditions experience a permanent income loss of $37 \%$, whereas this income loss is only $13 \%$ for those workers who experience job 
displacement during the best cyclical conditions (see table 2 and the corresponding discussion in Jacobson et al., 1993). In other words, the spread is $37 \%-13 \%=24 \% .{ }^{21}$ Clearly, focusing only on the most extreme cyclical conditions is overstating the cyclicality of income losses, but these estimates indicate a very strong cyclical component. Weinberg (2001) considers a sample of displaced workers of all tenure-levels (low- and high-tenure workers), and also finds a very strong cyclical component of the long-term earnings losses. More specifically, he finds that a one-standard deviation increase in industry growth increases post-displacement wages by $4 \%{ }^{22}$ Thus, the spread between good and bad cyclical conditions is $8 \%$ if we focus on one-standard deviations from the mean and $16 \%$ if we consider two-standard deviations from the mean.

Work by Solon, Barsky, and Parker (1994, Beaudry and DiNardo (1991), and Bils (1985) providesadditional evidence in favor of the view that earnings losses of displaced workers display a strong cyclical component. More specifically, Barsky and Solon (1989) and Bils (1985) show that after controlling for selectivity bias, aggregate wages decrease by approximately $1-1.5 \%$ in response to a one percent increase in the unemployment rate. Moreover, and more importantly for the current paper, Beaudry and DiNardo (1991) show that wages of new hires decrease on average by approximately $3-4.5 \%$ for every percent increase in the unemployment rate. Thus, assuming a spread of the unemployment rate of 5 percent between economic contractions and economic expansions, the last finding implies a variation

\footnotetext{
${ }^{21}$ Note that empirical result regarding the cyclical variation of $d$ reported by Jacobson et al. (1993) are derived exploiting differences across local labor markets. Put differently, the result is mainly based on cross-sectional variation, and the time-series inference drawn in this paper is therefore somewhat tentative.

${ }^{22}$ Weinberg (2001) exploits growth-rate differences across industries to identify the relationship between cyclical conditions and earnings losses of displaced workers. Thus, as in the case of Jacobson et al (1993), the business cycle implications of Weinberg's finding are not clear-cut. Moreover, Weinberg (2001) investigates low-frequency shocks to industry growth, whereas the current paper is concerned with short-term fluctuations.
} 
of income losses over the cycle of somewhere between $15 \%$ and $22.5 \%{ }^{23}$ Clearly, this type of evidence is silent about the persistence of income losses, but taken together with the evidence reported in Jacobson et al. (1993) they make a strong case in favor of the view that the permanent earnings losses of displaced workers have a large cyclical component.

Finally, we note that Keane and Wolpin (1997) estimate that the skill-level of white-collar workers depreciates by $30 \%$ for each year of unemployment. Combined with the fact that unemployment durations increase during recessions (Blanchard and Diamond, 1990), this finding provides additional evidence for the view that cyclical conditions affect the longterm losses of displaced workers. ${ }^{24}$ Notice that this effect goes beyond the transitory effect of unemployment on earnings due to forgone wage payments.

Guided by the above evidence, we assume that for high-tenure workers, the difference in the earnings looses of displaced workers between booms and recessions is $16 \%$. That is, we require that $d_{h L}-d_{h H}=.16$. Combined with the condition $.5 d_{h L}+.5 d_{h H}$, this yields $d_{h L}=.33$ and $d_{h H}=.17$. For low-tenure workers, we assume a spread of $d_{l L}-d_{l H}=.06$, which combined with the restriction $.5 d_{l L}=.5 d_{l H}=.12$ yields $d_{l L}=.15$ and $d_{l H}=.09$.

\section{Job Displacement Rates}

To complete the calibration of the job displacement process, we need to assign values for the job displacement probabilities $p_{s S}$. Jacobson et al (1993) report that in their sample of high-tenure workers, the fraction of workers that experience at least one job displacement event due to mass layoffs is equal to 28 percent over a time span of 13 years (see table 1

\footnotetext{
${ }^{23}$ Notice that a 5 percent spread in the unemployment rate is consistent with the fluctuations in the U.S. unemployment rate over the last 30 years. Note also that Imrohoroglu (1989) and Krusell and Smith $(1999,2002)$ use a spread in the unemployment rate that is even larger.

${ }^{24}$ Ljungqvist and Sargent (1998) and Pissarides (1992) are two examples of papers in the macroeconomic literature that heavily rely on this skill-depreciation effect of unemployment.
} 
in Jacobson et al (1993)). Assuming that the job displacement event is i.i.d. over time, this means that the probability of experiencing job displacement within a particular year is equal to $1-(1-.28)^{1 / 13}=.025$. An annual job displacement probability of $2.5 \%$, however, is likely to be an underestimate of the actual job displacement probability for the following reasons. First, the sample of workers displaced by mass-layoffs constructed by Jacobson et al. (1993) excludes many workers that ought to be counted as displaced workers, namely all those workers who lost their jobs for "exogenous reasons" but worked for firms that did not contract by at least 30 percent . Second, Jacobson et al. (1993) eliminate all displaced workers who subsequently report no earnings, which in their sample is a very large fraction of the total sample. The job displacement rates reported by Farber (1997), which are estimated using the DWS data, avoid these shortcomings, and are in this sense more representative. For male workers of age 35-44, Farber (1997) reports an average job displacement rate of .0384. This is in accordance with the job displacement rates reported by Stevens (1997) using the PSID data. Finally, we note that both the job displacement rates reported in the DWS and the PSID are likely to be under-estimates of the true job displacement probabilities because of recall bias (Topel, 1991). Finally, we note that measures of total rates of job loss are much larger and lie somewhere in between a quarterly rate of $2-10 \%$ (Hall, 1995). In our model economy, we choose the job displacement rates $p_{s S}$ so that the mean annual rate is 3 percent for high-tenure workers and 4 percent for low-tenure workers. That is, we require $.5 p_{h L}+.5 p_{h H}=.03$ and $.5 p_{l L}+.5 p_{l H}=.04$.

Jacobson et al. (1993) do not report the cyclical fluctuations in the job displacement rates in their data set. Using the DWS, Farber (1997) reports job displacement rates that have an annualized standard deviation of .0061. Stevens (1997) find similar variations in job displacement rates over the cycle using the PSID data. In our baseline model, we require the standard deviation of the job displacement rate for both high-tenure and low-tenure workers to be equal to .005. That is, we impose the restriction $\sqrt{.5\left(p_{h L}-.03\right)^{2}+.5\left(p_{h H}-.03\right)^{2}}=.005$ and 
$\sqrt{.5\left(p_{l L}-.04\right)^{2}+.5\left(p_{l H}-.04\right)^{2}}=.005$. Combining this with the restrictions $.5 p_{h L}+.5 p_{h H}=$ .03 and $.5 p_{l L}+.5 p_{l H}=.04$, we find $p_{h L}=.0035, p_{h H}=.0025, p_{l L}=.0045$, and $p_{l H}=.0035$. Finally, we choose the transition probability $q$ so that the implied stationary distribution of low- and high-tenure workers is $(.5, .5)$. This yields $q=.0312$.

\section{Other Earnings Risk}

To complete the calibration of the labor income process, it remains to find a value for the variance $\operatorname{var}\left(\log \left(1+\theta_{i, t+1}\right)\right)=\sigma^{2}$. To find this value, notice first that the average variance of log-income changes is

$$
\begin{aligned}
\sigma_{\log y}^{2} & \doteq \sum_{S} \pi_{S} \operatorname{var}\left(\left(\log y_{i, t+1}-\log y_{i t}\right) \mid S\right) \\
& =\sigma^{2}+\sum_{S} \pi_{S} \operatorname{var}\left(\log \left(1+\eta_{i, t+1}\right) \mid S\right)
\end{aligned}
$$

As argued before (see equation 4 ), the variance term $\sigma_{\log y}^{2}$ has been estimated by an extensive empirical literature. More specifically, the empirical literature on labor income risk has often used a random walk specification for the permanent component of labor income (Carroll and Samwick, 1997, Gottschalk and Moffitt, 1994, and Meghir and Pistaferri, 2004), or has used an $\operatorname{AR}(1)$ specification and then estimated a serial correlation coefficient close to one (Storesletten et al., 2004). Thus, this literature provide a direct estimate of $\sigma_{\log y}^{2}$. All the empirical studies use annual income data drawn from the PSID data set, and estimate an average variance of permanent income shocks between .022 and .033 for the pooled household/worker sample (a standard deviation between .15 and .18). In this paper, we calibrate the income process so that the implied value for $\sigma_{\log y}^{2}$ is equal to .022 (a standard deviation of .15). Using the already assigned values for the displacement parameters $p_{S}$ and $d_{S}$, equation (21) pins down $\sigma^{2}$. Using our previous values, we find $\sigma^{2}=.0207$ (a standard deviation of $\sigma=.1438)$ using $\eta_{i, t+1}$ of high-tenure workers in (23).

\section{Preference Parameters}


We choose the preference parameters as follows. We follow the bulk of the business cycle literature and choose an annual discount factor of $\beta=.96$. In comparison, Imrohoroglu (1989) also chooses $\beta=.96$, but Storesletten et al. (2001) pick $\beta=.95$. Krusell and Smith $(1999,2002)$ assume a stochastic discount factor with a mean of .95. For the degree of relative risk aversion, the standard choice in the macroeconomic literature is $\gamma=1$ (log-utility), and this is also our choice for the baseline model. However, we also report the results for $\gamma=1.5$ and $\gamma=2$. In comparison, Krusell and Smith $(1999,2002)$ use log-utility, Storesletten et al. (2001) focus on $\gamma=4$, and Imrohoroglu considers the two cases $\gamma=1.5$ and $\gamma=6$.

\section{Summary of Parameter Choices}

To sum up, for the baseline economy we choose $g=.02, \pi_{L}=\pi_{H}=.5, \sigma^{2}=.0207$, $p_{h L}=.035, p_{h H}=.025, p_{l L}=.0045, p_{l H}=.0035, q=.0312, d_{L}=.33, d_{H}=.17, \beta=.96$, and $\gamma=1$. Using equations (A11) and (A12) in the appendix, we find that the implied lending rate is $r=3.87 \%$ and the implied borrowing rate is $r_{b}=4.01$. In other words, the spread is $r_{b}-r=.14 \%$. This defines our baseline economy. However, we also consider the effect of an increase in risk aversion. When $\gamma=1.5$, the implied lending and borrowing rates become $r=2.89 \%$, respectively $r_{b}=3.11 \%$. When $\gamma=2$, we have $r=1.34 \%$ and $r_{b}=1.68 \%$.

\section{V.2. Results}

Tables 1 and 2 present the results of our quantitative study. The first column shows the cost of business cycles for different preferences parameters if business cycles are eliminated according to equation (19). If $\beta=.96$ and $\gamma=1$ (log-utility), which is the standard assumption in the macroeconomic literature, we have a welfare cost of business cycles that is equal to $\Delta=.571 \%$ for high-tenure workers and $\Delta=.303 \%$ for low-tenure workers. In comparison, for the same preference parameters, Lucas (1987) finds $\Delta=.05 \%$ using a 
representative-agent model. Thus, the cost of business cycles found here is roughly one order of magnitude larger than the ones found in Lucas (1987). Notice also that in the current model there are no fluctuations in aggregate income, so that the cost of business cycles is nil when markets are complete.

The next column shows the cost of business cycles when equation (18) is used to eliminate business cycles. In this case, the cost of business cycles are somewhat lower than before and roughly equal to the cost of business cycles when job displacement probabilities are constant $p_{L}=p_{H}$ (third column). Thus, introducing cyclical variations in job displacement probabilities amplifies the effect of cyclical variations in the income losses of displaced workers only by a sizable amount if we use the first method to eliminate business cycles.

The fourth column shows the cost of business cycles when, incorrectly according to the current paper, the researcher assumes that log-income changes are normally distributed. More precisely, according to the model, the standard deviation of log-income changes, $\sigma_{\log y}^{2}$, varies between $\sigma_{\log y}(L)=.1086$ and $\sigma_{\log y}(H)=.09862$ for high-tenure workers and $\sigma_{\log y}(L)=.09713$ and $\sigma_{\log y}(H)=.09524$ for low-tenure workers. In the fourth column of tables 1 and 2, we consider a labor income process that has, conditional on the aggregate state $S$, a symmetric two-state support, and choose the support so that we match the given $S$-dependent standard deviations. ${ }^{25}$ The results reported in the fourth column show that the cost of business cycles becomes negligible once the log-normal approach is taken. Put differently, the cyclical variation in income risk as measure by variations in $\sigma_{\log y}(S)$ are so small that the implied cost of business cycles become negligible. More generally, if the true distribution is not symmetric, then assuming symmetry as in Krebs (2003a) and Storesletten et al. (2001) can lead to a serious under-estimation of the cost of business cycles.

\footnotetext{
${ }^{25}$ This is the two-state approximation of the normal distribution using the Gauss-Hermite quadrature (Judd, 1998). The welfare results barely change if a four-state approximation is used, which suggests that the two-state approximation is already very good.
} 
Tables 1 and 2 also show how the cost of business cycles changes when the degree of risk aversion is varied. More specifically, we choose $\gamma=1.5$ and $\gamma=2$.. The cost of business cycles is increasing and convex in $\gamma$. For example, for high-tenure workers the cost of business cycles is $.571 \%$ if $\gamma=1, .887 \%$ if $\gamma=1.5$, and $1.37 \%$ if $\gamma=2$. The convexity of the cost of business cycles as a function of $\gamma$ has been emphasized by Storesletten et al. (2001).

Finally, we provide a welfare calculation similar to the one made in Hall (1995) and calculate the "welfare cost of recessions". More specifically, the two approaches (18) and (19) to the elimination of business cycles share one general feature that has been a fundamental principle in the argument put forward by Lucas $(1987,2003)$, namely that counter-cyclical stabilization policy can only reduce the severity of recessions by making the good times less attractive "by an equal amount". For the representative-agent model analyzed in Lucas (1987), this implicitly assumes that the relationship between government policy and macroeconomic variables (aggregate GDP) is linear. Moreover, for the incomplete-market model analyzed here, it means in addition that the relationship between earnings losses and aggregate GDP is linear. Any non-linearity would make both (18) and (19) invalid. In the most extreme case, we could imagine a situation in which counter-cyclical stabilization policy can eliminate recessions without affecting economic booms. That is, we could imagine that in the economy without business cycles we have $\bar{p}=p_{H}$ and $\bar{d}=d_{H}$, and then use the welfare formula (22) to compute $\Delta$, which in this case might be called the "cost of recessions". Notice that this procedure does not, as in Hall (1995), compute the cost of one recessions, but instead computes the welfare cost of all (future) recessions.

With preference parameters $\gamma=1$ and $\beta=.96$, we find a cost of recessions of 1.939 percent of lifetime consumption for high-tenure workers and 1.109 percent for low-tenure workers. If we increase the degree of risk aversion to $\gamma=2$, the we find $\Delta=3.408 \%$ for high-tenure workers and $\Delta=1.774 \%$ for low-tenure workers. Thus, the cost of recessions 
is quite large indeed. Clearly, this "cost of recessions" is an upper bound on the "cost of business cycles".

\section{Conclusion}

This paper analyzes the welfare costs of business cycles when workers face uninsurable job displacement risk that has a cyclical component. Using a simple dynamic general equilibrium model with incomplete markets, this paper shows the following: for sufficiently high degree of risk aversion (above one), the introduction of cyclical variations in the permanent earnings losses of displaced workers can generate arbitrarily large cost of business cycles even if there is no employment risk (displaced workers are immediately re-employed) and the second moments of the distribution of individual income shocks are (almost) constant over the cycle. In other words, the previous literature, which has either focused on cyclical fluctuations in employment risk or assumed that income changes of workers are (log)-normally distributed, might have severely under-estimated the cost of business cycles. In addition to the theoretical analysis, this paper also conducts a quantitative study of the cost of business cycles using empirical evidence about the permanent earnings losses of displaced U.S. workers. The quantitative analysis suggests that the cost of business cycles due to the cyclical variations in job displacement risk is quite substantial. 


\section{Appendix 1}

\section{Proof of proposition 3.}

We have

$$
\begin{gathered}
\operatorname{var}\left[y_{i, t+1} / y_{i t} \mid S_{t+1}\right]=\operatorname{var}\left[(1+g)\left(1+\theta_{i, t+1}\right)\left(1+\eta_{i, t+1}\right) \mid S_{t+1}\right] \\
=(1+g)^{2} \operatorname{var}\left[\theta_{i, t+1}+\eta_{i, t+1}+\theta_{i, t+1} \eta_{i, t+1} \mid S_{t+1}\right], \\
=(1+g)^{2}\left(\operatorname{var}\left[\theta_{i, t+1} \mid S_{t+1}\right]+\operatorname{var}\left[\eta_{i, t+1} \mid S_{1+1}\right]+\operatorname{var}\left[\theta_{i, t+1} \eta_{i, t+1} \mid S_{t+1}\right]\right) \\
=(1+g)^{2}\left(\operatorname{var}\left[\theta_{i, t+1} \mid S_{t+1}\right]+\operatorname{var}\left[\eta_{i, t+1} \mid S_{1+1}\right]+\operatorname{var}\left[\theta_{i, t+1} \mid S_{t+1}\right] \operatorname{var}\left[\eta_{i, t+1} \mid S_{t+1}\right]\right),
\end{gathered}
$$

where the third and fourth lines follow from $\operatorname{cov}\left[\theta_{i, t+1}, \eta_{i, t+1} \mid S_{t+1}\right]=0$ and $E\left[\theta_{i, t+1} \mid S_{t+1}\right]=$ $E\left[\eta_{i, t+1} \mid S_{t+1}\right]=0$

To simplify the notation, we consider the case of two aggregate states: $S=L, H$. We further assume $d_{H}=0$ and $p_{L}=p_{H}=p .^{26}$ That is, if $S_{t+1}=H$, then $\eta_{i, t+1}=0$. Thus, for $S_{t+1}=H$ we have:

$$
\operatorname{var}\left[y_{i, t+1} / y_{i t} \mid H\right]=(1+g)^{2} e^{\sigma^{2}}-1
$$

On the other hand, for $S_{t+1}=L$ we have:

$$
\operatorname{var}\left[y_{i, t+1} / y_{i t} \mid L\right]=(1+g)^{2}\left[e^{\sigma^{2}}-1+\frac{p d^{2}}{1-p}+\left(e^{\sigma^{2}}-1\right) \frac{p d^{2}}{1-p}\right]
$$

Take any $\epsilon>0$ and $d$ with $0<d<1$, and choose $p=\frac{\epsilon}{\epsilon+d^{2}(1+g)^{2} e^{\sigma^{2}}}$. Clearly, by construction we have $0<p<1$ and

$$
\begin{aligned}
\operatorname{var}\left[y_{i, t+1} / y_{i t} \mid L\right]-\operatorname{var}\left[y_{i, t+1} / y_{i t} \mid H\right]= & (1+g)^{2} \frac{p d^{2}}{1-p} e^{\sigma^{2}} \\
& =\epsilon .
\end{aligned}
$$

\footnotetext{
${ }^{26}$ Notice that in this case, both approaches to the elimination of business cycles (18) and (19) lead to the same result.
} 
That is, the choice of $p=\frac{\epsilon}{\epsilon+d^{2}(1+g)^{2} e^{\sigma^{2}}}$ ensures that the cyclical variation in the second moments of the distribution of income growth rates is always equal to $\epsilon$, and therefore arbitrarily small. We now show that for any number $\bar{\Delta}>0$ we can always find a number $d$ with $0<d<1$ (and a corresponding number $p=\frac{\epsilon}{\epsilon+d^{2}(1+g)^{2} e^{\sigma^{2}}}$ ) so that the implied welfare cost of business cycles is equal to $\bar{\Delta}$.

To simplify notation, introduce $c=(1+g)^{2} e^{\sigma^{2}}>0$, so that $p=\frac{\epsilon}{\epsilon+c d^{2}}$. Consider the cost of business cycles (21) for $\gamma>1$ (the argument for the log-utility case is the same). Notice first that the expectations term in (21) can be written as

$$
\beta E\left[\left(1+\theta_{i, t+1}\right)^{1-\gamma}\left(1+\eta_{i, t+1}\right)^{1-\gamma}\right]=\beta e^{-\frac{1}{2} \gamma(1-\gamma) \sigma^{2}} f(\epsilon, d)
$$

and

$$
\beta E\left[\left(1+\theta_{i, t+1}\right)^{1-\gamma}\left(1+\bar{\eta}_{i, t+1}\right)^{1-\gamma}\right]=\beta e^{-\frac{1}{2} \gamma(1-\gamma) \sigma^{2}} \bar{f}(\epsilon, d)
$$

where we introduced

$$
f(\epsilon, d)=\pi_{L}\left(\frac{\epsilon}{\epsilon+c d^{2}}(1-d)^{1-\gamma}+\left(1-\frac{\epsilon}{\epsilon+c d^{2}}\right)\left(1+\frac{\frac{\epsilon}{\epsilon+c d^{2}} d}{1-\frac{\epsilon}{\epsilon+c d^{2}}}\right)^{1-\gamma}\right)+\pi_{H}
$$

and

$$
\bar{f}(\epsilon, d)=\frac{\epsilon \pi_{L}}{\epsilon+c d^{2}}\left(1-d \pi_{L}\right)^{1-\gamma}+\left(1-\frac{\epsilon \pi_{L}}{\epsilon+c d^{2}}\right)\left(1+\frac{\frac{\epsilon \pi_{L}}{\epsilon+c d^{2}} d \pi_{L}}{1-\frac{\epsilon \pi_{L}}{\epsilon+c d^{2}}}\right)^{1-\gamma}
$$

From the fact that $\eta_{i}$ is a mean-preserving spread of $\bar{\eta}_{i}$, it follows immediately that

$$
\bar{f}(\epsilon, d)<f(\epsilon, d)
$$

for any $\gamma>1$. Further, for any $\epsilon>0$, there is a number $d$ with $0<d<1$ so that

$$
f(\epsilon, d)=\left(\beta e^{-\frac{1}{2} \gamma(1-\gamma) \sigma^{2}}\right)^{-1}
$$

The last equation (A8) follows from the continuity of $f$ in conjunction with $f(\epsilon, 0)=\pi_{L}+$ $\pi_{H}=1, \lim _{d \rightarrow-1} f(\epsilon, d)=+\infty$, and the fact that the right-hand-side of (A8) is strictly 
greater than one by assumption (7). Using (A5)-(A7) in the welfare expression (22) yields the desired result, namely the existence of a $d$ and $p$ so that (A4) is satisfied and the cost of business cycles is equal to $\bar{\Delta}$. 


\section{Appendix 2}

\section{A Model with Low-Tenure and High-Tenure Workers}

In this appendix, we extent the model discussed in section III to the case in which there are two different types of workers, low-tenure workers and high-tenure workers, who face different degrees of displacement risk.

Suppose that the income process of all workers is still given by (1). Assume further that $\theta_{i t}$ is defined as before, but that $\eta_{i t}$ is now given by

$$
\eta_{i, t+1}^{s}= \begin{cases}-d_{s S^{\prime}} & \text { with probability } p_{s S} \text { if } s_{i t}=s \text { and } S_{t+1}=S \\ \frac{p_{s S} d_{s S}}{1-p_{s S}} & \text { with probability }\left(1-p_{s S}\right) \text { if } S_{t+1}=S\end{cases}
$$

where $s=l$ if worker $i$ is a low tenure worker in period $t$ and $s=h$ if he is a high-tenure worker in period $t$. Clearly, high-tenure workers become low-tenure workers whenever they are displaced. That is, the transition probability of moving from $s_{i t}=h$ to $s_{i, t+1}=l$ if $S_{t+1}=S$ is equal to $p_{h S}$. To keep the model tractable, we assume that low-tenure become high-tenure workers in a stochastic fashion. That is, we assume that the probability of a low-tenure worker becoming a high-tenure worker is the same for all low-tenure workers and equal to $q$.

As in the basic model, we assume that workers can borrow and lend at a risk-free rate. However, in contrast to section III, we now assume there are two distinct risk-free rates, a borrowing rate, $r_{b}$, and a lending rate $r$ (with $r \leq r_{b}$ ). Thus, the modified budget constraint reads

$$
\begin{gathered}
a_{i, t+1}=\left\{\begin{array}{c}
(1+r) a_{i t}+y_{i t}-c_{i t} \quad \text { if } \quad a_{i t} \geq 0 \\
\left(1+r_{b}\right) a_{i t}+y_{i t}-c_{i t} \quad \text { if } \quad a_{i t}<0
\end{array}\right. \\
a_{i, t+1} \geq-M \quad, \quad a_{i 0}=0
\end{gathered}
$$

Finally, preference of all workers are given by (6).

We define an equilibrium as in section III. It is again straightforward to show that $c_{i t}=y_{i t}$ 
and $a_{i t}=0$ is an equilibrium allocation if the equilibrium interest rates are given by

$$
\begin{gathered}
1+r=\left(\beta E\left[\left(\frac{y_{i, t+1}}{y_{i t}}\right)^{-\gamma} \mid s_{i t}=h\right]\right)^{-1} \\
=\left(\beta(1+g)^{-\gamma} e^{\frac{1}{2} \gamma(\gamma+1) \sigma^{2}} \sum_{S} \pi_{S}\left[p_{h S}\left(1-d_{h S}\right)^{-\gamma}+\left(1-p_{h S}\right)\left(1+\frac{p_{h S} d_{h S}}{1-p_{h S}}\right)^{-\gamma}\right]\right)^{-1}
\end{gathered}
$$

and

$$
\begin{gathered}
1+r_{b}=\left(\beta E\left[\left(\frac{y_{i, t+1}}{y_{i t}}\right)^{-\gamma} \mid s_{i t}=l\right]\right)^{-1} \\
=\left(\beta(1+g)^{-\gamma} e^{\frac{1}{2} \gamma(\gamma+1) \sigma^{2}} \sum_{S} \pi_{S}\left[p_{l S}\left(1-d_{l S}\right)^{-\gamma}+\left(1-p_{l S}\right)\left(1+\frac{p_{l S} d_{l S}}{1-p_{l S}}\right)^{-\gamma}\right]\right)^{-1}
\end{gathered}
$$

Here we assume that, without loss of generality, the right-hand-side of (A11) is smaller than the right-hand-side of (A12). That is, we assume that the high-tenure workers are the high-risk workers.

Given the allocation $c_{i t}=y_{i t}$, we can use the specification of the labor income process and preferences to compute welfare (expected lifetime utility) for each group of workers. More precisely, notice first that welfare of low- and high-tenure workers has to satisfy the following recursive equation:

$$
\begin{array}{r}
V_{h}\left(y_{i}\right)=\frac{y_{i}^{1-\gamma}}{1-\gamma}+\beta \sum_{S} \pi_{S} p_{h S} E\left[V_{l}\left((1+g)\left(1+\theta_{i}\right)\left(1-d_{h S}\right) y_{i}\right)\right] \\
+\beta \sum_{S} \pi_{S}\left(1-p_{h S}\right) E\left[V_{h}\left((1+g)\left(1+\theta_{i}\right)\left(1+\frac{p_{h S} d_{h S}}{1-p_{h S}}\right) y_{i}\right)\right]
\end{array}
$$

and

$$
\begin{aligned}
& V_{l}\left(y_{i}\right)=\frac{y_{i}^{1-\gamma}}{1-\gamma}+\beta \sum_{S} \pi_{S} p_{l S} E\left[V_{l}\left((1+g)\left(1+\theta_{i}\right)\left(1-d_{l S}\right) y_{i}\right)\right] \\
& +\beta \sum_{S} \pi_{S}\left(1-p_{l S}\right)(1-q) E\left[V_{l}\left((1+g)\left(1+\theta_{i}\right)\left(1+\frac{p_{l S} d_{l S}}{1-p_{l S}}\right) y_{i}\right)\right]
\end{aligned}
$$




$$
+\beta \sum_{S} \pi_{S}\left(1-p_{l S}\right) q E\left[V_{h}\left((1+g)\left(1+\theta_{i}\right)\left(1+\frac{p_{l S} d_{l S}}{1-p_{l S}}\right) y_{i}\right)\right]
$$

Equation (A13) can be directly solved by the methods of undetermined coefficients. That is, it is straightforward that $V_{s}\left(y_{i}\right)=a_{s} \frac{y^{1-\gamma}}{1-\gamma}$ solves (A13) if and only of the coefficients $a_{s}$ solve the linear equations system:

$$
\begin{gathered}
\left(1-\beta c \sum_{S} \pi_{S}\left(1-p_{h S}\right)\left(1+\frac{p_{h S} d_{h S}}{1-p_{h S}}\right)^{1-\gamma}\right) a_{h}-\left(\beta c \sum_{S} \pi_{S} p_{h S}\left(1-d_{h S}\right)^{1-\gamma}\right) a_{l}=1 \\
\left(1-\beta c \sum_{S} \pi_{S}\left(p_{l S}\left(1-d_{l S}\right)^{1-\gamma}+\left(1-p_{l S}\right)(1-q)\left(1+\frac{p_{l S} d_{l S}}{1-p_{l S}}\right)^{1-\gamma}\right)\right) a_{l} \\
-\left(\beta c \sum_{S} \pi_{S}\left(1-p_{l S}\right) q\left(1+\frac{p_{l S} d_{l S}}{1-p_{l S}}\right)^{1-\gamma}\right) a_{h}=1
\end{gathered}
$$

where the constant $c$ is given by:

$$
c=(1+g)^{1-\gamma} e^{\frac{1}{2} \gamma(\gamma-1) \sigma^{2}} .
$$

Repeating the argument made in section IV, the cost of business cycles for a worker of type $s$ becomes:

$$
\Delta_{s}=\left(\frac{\bar{a}_{s}}{a_{s}}\right)^{\frac{1}{1-\gamma}}-1
$$

where $\left(a_{l}, a_{h}\right)$ is the solutions to (A14) using state-dependent job displacement parameters $p_{S}$ and $d_{S}$ (economy with business cycles) and $\left(\bar{a}_{l}, \bar{a}_{h}\right)$ is the solution to (A14) using stateindependent job displacement parameters $\bar{p}$ and $\bar{d}$ (economy without business cycles. 


\section{References}

Acemoglu, D., and R. Shimer (2001) "Productivity Gains from Unemployment Insurance," European Economic Review 44: 1195-1224.

Atkeson, A., and C. Phelan (1994) "Reconsidering the Cost of Business Cycles with Incomplete Markets," NBER Macroeconomics Annual, MIT Press, Cambridge, MA, pp. 187-207.

Beaudry, P., and J. DiNardo (1991) "The Effect of Implicit Contracts on the Movement of Wages Over the Business Cycle," Journal of Political Economy 99: 665-688.

Beaudry, P., and C. Pages (2001) "The Cost of Business Cycles and the Stabilization Value of Unemployment Insurance," European Economic Review, 45: 1545-1572.

Bils, M. (1985) "Real Wages Over the Business Cycle: Evidence from Panel Data," Journal of Political Economy 93: 666-689.

Blanchard, O., and P. Diamond (1990) "The Cyclical Behavior of the Gross Flows of U.S. Workers," BPEA 2: 85-143.

Brav, A., Constantinides, G., and C. Geczy (2002) "Asset Pricing with Heterogeneous Consumers and Limited Participation: Empirical Evidence," Journal of Political Economy 110: $793-825$.

Caballero, R., and M. Hammour (1994) "The Cleansing Effect of Recessions," American Economic Review 84: 1350-1368.

Carroll, C., and A. Samwick (1997) "The Nature of Precautionary Wealth," Journal of Monetary Economics 40: 41-72.

Carroll, C. (1997) "Buffer-Stock Saving and the Life-Cycle/Permanent-Income Hypothesis," Quarterly Journal of Economics 112: 1-55.

Constantinides, G. and D. Duffie (1996) "Asset Pricing with Heterogeneous Consumers," Journal of Political Economy, 104: 219-240.

Deaton, A. (1991) "Saving and Liquidity Constraints," Econometrica 59: 1221-1248.

Geweke, J., and M. Keane (2000) "An Empirical Analysis of Male Income Dynamics in the PSID: 1968-1989," Journal of Econometrics 96: 293-356.

Gibbons, R., and L. Katz (1991) "Layoffs and Lemmons," Journal of Labor Economics 9: 351-380.

Gomez, J., Greenwood, J., and S. Rebelo (2001) "Equilibrium Unemployment," Journal of Monetary Economics 48: 109-152.

Gottschalk, P., and R. Moffitt (1994) "The Growth of Earnings Instability in the U.S. 
Labor Market," Brookings Papers on Economic Activity 2: 217-254.

Hall, R. (1995) "Lost Jobs," Brookings Papers on Economic Activity, 1: 221-273.

Haltiwanger, J. "Aggregate Growth: What Have We Learned From The Microeconomic Evidence?" Working Paper, University of Maryland.

Hubbard, G., Skinner, J., and S. Zeldes (1994) "The Importance of Precautionary Motives in Explaining Individual and Aggregate Savings," Carnegie-Rochester Conference Series on Public Policy 40: 59-126.

Imrohoroglu, A. (1989) "Costs of Business Cycles with Indivisibilities and Liquidity Constraints," Journal of Political Economy, 1364-83.

Jacobson, L., LaLonde, R., and D. Sullivan (1993) "Earnings Losses of Displaced Workers," American Economic Review 83: 685-709.

Jovanovic, B. (1979) "Firm-Specific Capital and Turnover," Journal of Political Economy 87: $1246-1260$.

Jovanovic, B. (2003) "Asymmetric Cycles," Working Paper, NYU.

Judd, K. (1998) Numerical Methods in Economics, Cambridge, MA: MIT Press.

Kambourov, G., and I. Manovskii (2002) "Occupational Specificity of Human Capital," Working Paper, UPenn.

Keane, M., and K. Wolpin (1997) "The Career Decisions of Young Men," Journal of Political Economy 105: 473-522.

Kletzer, L., and R. Fairlie (2003) "The Long-Term Costs of Job Displacement of Young Adult Workers," Industrial and Labor Relations

Krebs, T. (2003a) "Growth and Welfare Effects of Business Cycles in Economies with Idiosyncratic Human Capital Risk," The Review of Economic Dynamics 6: 846-868.

Krebs, T. (2003b) "Human Capital Risk and Economic Growth," The Quarterly Journal of Economics 118: 709-744.

Krebs, T. (2004) "Testable Implications of Consumption-Based Asset Pricing Models with Incomplete Markets," Journal of Mathematical Economics, 40: 191-206.

Krusell, P., and A. Smith (1999) "On the Welfare Effects of Business Cycles," Review of Economic Dynamics, 2: 247-272.

Krusell, P., and A. Smith (2002) "Revisiting the Welfare Effects of Eliminating Business Cycles," Working Paper, Carnegie-Mellon University.

Ljungqvist, L., and T. Sargent (1998) "The European Unemployment Dilemma," Journal of Political Economy 106: 514-550. 
Lucas (1978) "Asset Prices in an Exchange Economy," Econometrica 46: 1429-1446.

Lucas, R. Models of Business Cycles. New York: Blackwell, 1987.

Lucas, R. (2003) "Macroeconomic Priorities," American Economic Review 93: 1-14.

Manuelli, R., Jones, L., Siu, H., and E. Stacchetti (2003) "Fluctuations in Convex Models of Endogenous Growth: Growth Effects," Working Paper, University of Wisconsin.

Meghir, C. and L. Pistaferri (2004) "Income Variance Dynamics and Heterogeneity," Econometrica

Neal, D. (1995) "Industry-Specific Human Capital: Evidence from Displaced Workers," Journal of Labor Economics 13: 653-677.

Pissaridies, C. (1992) "Loss of Skill During Unemployment and the Persistence of Employment Shocks," Quarterly Journal of Economics 1371-1260.

Rogerson, R., and M. Schindler (2002) "The Welfare Cost of Worker Displacement," Journal of Monetary Economics 49: 1213-35.

Ruhm, C. (1991) "Are Workers Permanently Scarred by Job Displacement?" American Economic Review 81: 319-324.

Solon, G., Barsky, R., and J. Parker "Measuring the Cyclicality of Real Wages: How Important is the Composition Bias?" Quarterly Journal of Economics 1- 25.

Stevens, A. (1997) "Persistent Effects of Job Displacement: The Importance of Multiple Job Losses," Journal of Labor Economics 15: 165-188.

Storesletten, K., Telmer, C., and A. Yaron (2001) "The Welfare Cost of Business Cycles Revisited: Finite Lives and Cyclical Variations in Idiosyncratic Risk," European Economic Review.

Storesletten, K., Telmer, C., and A. Yaron (2004) "Cyclical Dynamics of Labor Market Risk," Journal of Political Economy

Topel, R. "Specific Capital, Mobility, and Wages: Wages Rise with Job Seniority," Journal of Political Economy 99: 145-176.

Weinberg, B. (2001) "Long-Term Wage Fluctuations with Industry-Specific Human Capital," Journal of Labor Economics 19: 231-264. 


\section{Table I. Cost of Business Cycles: High-Tenure Workers ${ }^{27}$}

\begin{tabular}{lrrrc}
\hline \hline Model & Method 1 & Method 2 & $p_{L}=p_{H}$ & log-normal \\
\hline \hline$\beta=.96, \gamma=1$ & $.571 \%$ & $.315 \%$ & $.312 \%$ & $.001 \%$ \\
$\beta=.96, \gamma=1.5$ & $.887 \%$ & $.506 \%$ & $.502 \%$ & $.002 \%$ \\
$\beta=.96, \gamma=2$ & $1.370 \%$ & $.808 \%$ & $.803 \%$ & $.004 \%$ \\
\hline \hline
\end{tabular}

\section{Table II. Cost of Business Cycles: Low-Tenure Workers ${ }^{28}$}

\begin{tabular}{lcccc}
\hline \hline Model & Method 1 & Method 2 & $p_{L}=p_{H}$ & log-normal \\
\hline \hline$\beta=.96, \gamma=1$ & $.303 \%$ & $.166 \%$ & $.164 \%$ & $.001 \%$ \\
$\beta=.96, \gamma=1.5$ & $.461 \%$ & $.260 \%$ & $.257 \%$ & $.002 \%$ \\
$\beta=.96, \gamma=2$ & $.743 \%$ & $.432 \%$ & $.426 \%$ & $.004 \%$ \\
\hline \hline
\end{tabular}

\footnotetext{
${ }^{27}$ Cost of business cycles are expressed as percentage of lifetime consumption. Job displacement process of high-tenure workers. The first two columns assume displacement probabilities $p_{L}=.035$ and $p_{H}=.025$ and corresponding income losses of $d_{L}=.33$ and $d_{H}=.17$. Method 1 uses equation (19) and method 2 equation (18) to eliminate business cycles. The column $p_{L}=p_{H}$ has constant displacement probabilities of $p_{L}=p_{H}=.03$ using the same income losses.

${ }^{28}$ The first column assumes displacement probabilities $p_{L}=.045$ and $p_{H}=.035$ and corresponding income losses of $d_{L}=.15$ and $d_{H}=.09$. The column $p_{L}=p_{H}$ has constant displacement probabilities of $p_{L}=p_{H}=.04$ using the same income losses.
} 